\title{
Effect of Crankshaft and Crankcase Material Stiffness on Load Distribution in Main Bearings
}

\section{H. Karimaei ${ }^{*}$ and H. R. Chamani ${ }^{2}$}

${ }^{1}$ Aerospace Research Institute, Ministry of Science, Research and Technology, Tehran, 14668-834, Iran

*Email: karimaei@ari.ac.ir

Phone: +982188366030; Fax: +982188362011

${ }^{2}$ Fatigue and Fracture Laboratory, Center of Excellence in Experimental Solid Mechanic and Dynamics, School of Mechanical Engineering, Iran University of Science and Technology, Tehran, 16846, Iran

\begin{abstract}
In multi-cylinder diesel engines, hydrodynamic pressure distribution of main bearings has significant effect on the load distribution applied on engine crankcase, therefore, has an effect on the stress distribution and deflection of crankcase. Flexibility of crankshaft and crankcase assembly has significant effect on load distribution in engine main bearings. In this paper, the effect of elastic deformations of both crankshaft and crankcase on the load distribution in the main bearings is studied. Considering deformations of crankcase and crankshaft together with the elasto-hydrodynamic (EHD) analysis of main bearing is vital to obtain the realistic load distribution and accurate main bearing performance. At the beginning, the results of flexible body dynamic analysis of engine crank train with considering EHD joint for main bearings are presented and the main bearing force and moment are compared with rigid body dynamic analysis. Then, the effects of crankshaft and crankcase flexibilities on main bearing force and moment are studied. Several models with different flexibilities and stiffness of crankcase and crankshaft were prepared using Elasto-hydrodynamic simulation of diesel engine main bearings. According to the results, the load distribution on the engine main bearings and consequently the bearing shell deformation are affected by crankcase and crankshaft elasticities. A fast and time-saving method to obtain reasonably accurate results is proposed in the present paper.
\end{abstract}

Keywords: Elasto-hydrodynamic; heavy-duty diesel engine; main bearing; flexibility; stiffness.

\section{NOMENCLATURE}

$C_{R}: \quad$ Bearing radial clearance

$e_{x}$ : Eccentricity in $\mathrm{X}$ direction

$e_{y}: \quad$ Eccentricity in Y direction

$Z$ : $\quad$ Axial position of bearing nodes

$\alpha$ : $\quad$ Pressure viscosity coefficient

$\alpha_{x}: \quad$ Misalignment around $\mathrm{X}$ axis

$\alpha_{y}: \quad$ Misalignment around $\mathrm{Y}$ axis $\beta$ : $\quad$ Circumferential coordinate of bearing

$\delta$ : Radial deformation of the bearing surface

$\eta_{0}: \quad$ Viscosity at ambient pressure

$\eta: \quad$ Viscosity

$\theta: \quad$ Fill ratio 


\section{INTRODUCTION}

Engine designers are increasingly using more advanced simulation techniques to reduce design time and cost and at the same time to improve the accuracy of the design to limit the number of required validation tests. In recent years, the requirement for higher output power has imposed higher bearing load in heavy-duty diesel engines. On the other hand, due to competition in the market, engine parts should be durable enough, and the least failure should occur in critical parts. Therefore, a precise analysis technique to optimise engine components is needed [1].

At the initial stage of engine design, the key dimensions of the crankshaft are selected to shape the whole engine configuration. Main bearing forces and moments besides the bearing lubrication performance are the key factors to determine the crankshaft and bearing housing dimensions. The stiffness of crankshaft and crankcase and dimensions of the main bearings have a significant effect on the load characteristic over the main bearings. The design of these components can be optimised according to the load level. Thus, at the stage of concept design, the analysis procedure of crankshaftcrankcase interaction should be not only accurate enough, but also should be done fast enough to save the time.

Journal bearing load shape of multi-cylinder diesel engines has a significant effect on lubrication-related parameters such as minimum oil film thickness, maximum oil film pressure and, consequently, wear of bearing shells. Therefore, it can be used as design criterion of related components such as the crankshaft, main bearings and crankcase. The journal pin load distribution over the journal bearing, as opposed to crank pin load which has been simply calculated from cylinder pressure and inertia forces, is very complex and depends on different conditions. There are different traditional methods to calculate the main bearing load as reviewed in [2] and [3]. Cho et al. [4], experimentally measured the main bearing force components of a four-in-line engine, in vertical and horizontal directions, using two different ring type load cells, mounted in each main bearing cap bolt. They compared the experimental results with the theoretical results obtained by the statically determination method. It is illustrated that the statically determination method is not in agreement with the experimental results.

The crankshaft is supported by multiple bearings. The elasticity of crankshaft, clearance of journal bearings, elasto-hydrodynamic (EHD) oil film pressure distribution of journal bearings and elasticity of crankcase are the key factors that affect the crankshaft and crankcase deflection as well as load distribution of crankshaft over the journal bearings. The multi-body dynamic (MBD) analysis of crankshaft with considering the elastic interaction of the crankshaft and crankcase was studied by different researchers [5-7].

Cicek and Celik [8] took the advantages of the failure modes and effects analysis (FMEA) to adapt innovative marine technologies integrated with the operational aspects to prevent crankcase explosion failure onboard ships. They attempted to improve the machinery system reliability and enhance operational safety concepts on board ship. Pratik et al. [9] did a live case study of the premature failure of the crankcase is selected as per the requirement of the user. This paper focuses on a critical survey of literature and thereby use of methodologies to find out the critical area through static analysis. The analysis result validates the point of high stress where the crack was initiated. Analysis of crankshaft has also been performed, and its analysis proves to be safe in the given working conditions. Rozhdestvensky et al. [10] present the solution to the interconnected problem of main bearings dynamics for the forced internal combustion (IC) engine. It 
analyses not only the influence of macro geometry parameters of each main bearing and the influence of non-Newtonian properties of lubricant but also elastic characteristics of a crankshaft and crankcase and supports displacements caused by the thermal deformation of an engine crankcase. The research shows the necessity of applying the integrated approaches which allow considering both the features of autonomous bearings and many facts of their interaction simultaneously.

In this paper, the effect of both crankshaft and crankcase flexibilities on the main bearing load distribution of the diesel engine is studied. The full assembly of crankshaft bearings of a V12 heavy-duty diesel engine was modelled by AVL/Excite ${ }^{\circledR}$ software [11]. Several models with different stiffness of crankcase and crankshaft were analysed using an EHD simulation of diesel engine journal bearings. A fast and time-saving method to obtain reasonably accurate results is proposed. The main bearing analysis of the medium speed turbocharged V12 heavy duty diesel engine is conducted. The power of the base engine is $1200 \mathrm{~kW}$, and its rated speed is $1500 \mathrm{rpm}$. In this engine, the main bearing cap is mounted on the ladder frame and is assembled to the crankcase.

\section{METHODOLOGY}

In the beginning, the results of flexible body dynamic analysis of engine crank train with considering EHD joint for main bearings are presented and the main bearing force and moment are compared with rigid body dynamic analysis. Then, the effects of crankshaft and crankcase flexibilities on main bearing force and moment are studied. The flexibility of crankshaft can be changed by changing its Young's modulus. Many cases with different flexibility conditions of crankcase as well as different joint types are also conducted.

\section{Elasto-Hydrodynamic Method}

In current work, the bearing analysis was performed using the EHD method. AVLIExcite ${ }^{\circledR}$ software is a powerful tool for bearing analysis. Therefore, it was employed for this purpose. The detailed theory of EHD analysis has been published in [12-15], and here just the major principles are discussed. EHD method is based on the Reynolds Eq. (1) [11] solved in the bearing surface. Eq. (1) includes the mass-conserving cavitation model, which is considered with an additional variable, clearance fill ratio $\theta$. For $\theta=1$, the equation becomes the ordinary Reynold's equation. The Reynolds equation is solved to obtain pressure $(p)$ in the lubrication region and filling factor $(\theta)$ in the cavitation region. The filling factor is used to model the cavitation effects and is defined as the fraction of volume filled with oil to the total volume [11 and 16]. Filling factor equal one indicates the gap is fully filled with oil and zero indicates a completely empty gap. The coordinate system $(\mathrm{x}, \mathrm{y}, \mathrm{z})$ is displayed in Figure 1.

$$
\frac{\partial}{\partial x}\left(\frac{\theta h^{3}}{12 \eta} \frac{\partial p}{\partial x}\right)+\frac{\partial}{\partial z}\left(\frac{\theta h^{3}}{12 \eta} \frac{\partial p}{\partial z}\right)=\left(\frac{u_{1}+u_{2}}{2}\right) \frac{\partial(\theta h)}{\partial x}+\frac{\partial(\theta h)}{\partial t}
$$

In an EHD analysis, the effect of the elastic displacement of the bearing surface has to be included. The oil film thickness $(h)$ regarding the initial geometrical clearance $(C)$, misalignment of the shaft $(e)$, and elastic deformation $(\delta)$ is expressed by Eq. (2). 
$\mathrm{h}(\beta, \mathrm{z})=\mathrm{C}_{\mathrm{R}}-\left(\mathrm{e}_{\mathrm{x}}+\alpha_{\mathrm{y}} \mathrm{Z}\right) \cos \beta-\left(\mathrm{e}_{\mathrm{y}}+\alpha_{\mathrm{x}} \mathrm{Z}\right) \sin \beta+\delta(\beta, \mathrm{z})$

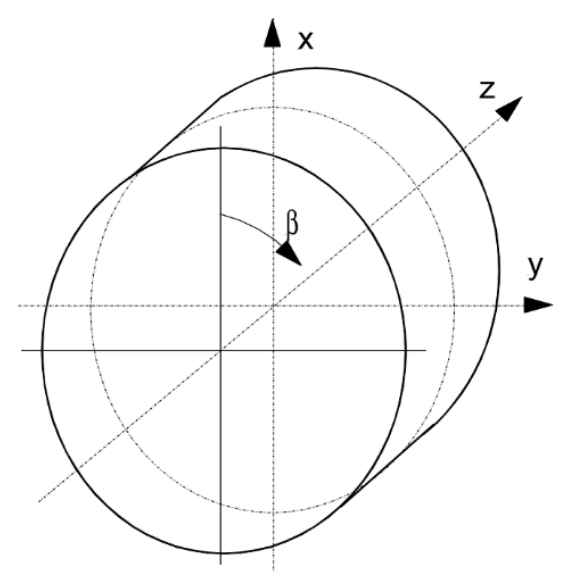

Figure 1. Coordinate system (x, y, z).

Radial deformation of the bearing surface is obtained from the nodal displacements of the bearing surface along the radial and circumferential axes. The nodal displacements of the bearing surface are determined by solving the equations of motion for the condensed bearing structure. Here, Barus' equation is utilised to define the oil viscosity:

$$
\eta=\eta_{0} \mathrm{e}^{\alpha \mathrm{p}}
$$

where, $\eta_{0}$ is the oil viscosity at the ambient pressure and $\alpha$ is the pressure viscosity coefficient.

\section{Modelling and FE Model Reduction}

The detailed finite element model of crankshaft and crankcase is very complex with about one million DOFs. Therefore, the dynamic analysis considering complete DOFs of entire nodes is expensive and time-consuming. To reduce the computation time, the FE parts were condensed (by static or dynamic condensation method) into just some nodes which are in contact with other parts (using different types of joint) or are under loads. The condensed FE model of the crankcase is obtained by solving the sub-structuring analysis and the mass and stiffness matrixes of the condensed FE parts are extracted using the substructuring method. In the present work, ABAQUS ${ }^{\circledR}$ software was used for this purpose.

There are two types of crankshaft model which represent the entire FE characteristics of crankshaft assembly (crankshaft, flywheel and torsional damper), as follows:

i. NOD6: Crankshaft assembly is represented by beam and mass elements, and each node has 6 DOF.

ii. CON6: Crankshaft assembly is represented by 3D solid elements, and each node has 3 DOF.

In this paper, the crankshaft was modelled with NOD6 body in AVL/Excite ${ }^{\circledR}$ Shaft-Modeler. Yilmaz [15] used the beam elements for modelling the crankshaft as a flexible body, and he indicated that crankshaft modelled by beam elements leads to more accurate results. Figure 2 shows the V12 crankshaft beam model created by AVL ${ }^{\circledR}$ shaft 
modeller. To evaluate the beam model of the crankshaft, the natural frequency of the beam model was compared with the FE solid element model. The results illustrated that the beam model has enough accuracy and the error is lower than $4 \%$. The first mode shape of the crankshaft (1st bending mode) can be seen in Figure 3.

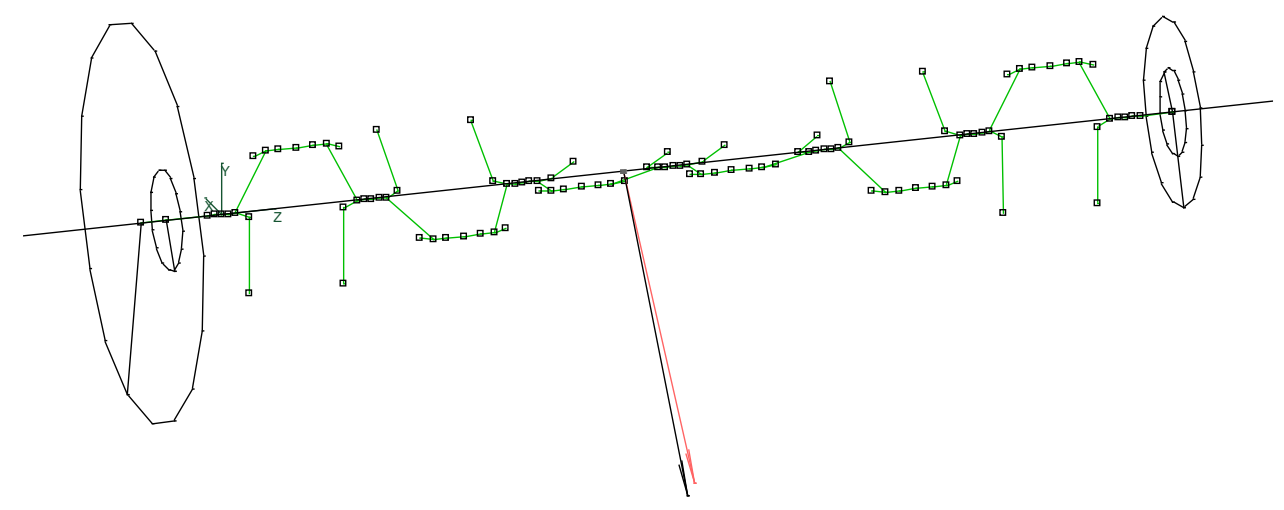

Figure 2. V12 crankshaft created by AVL/Excite ${ }^{\circledR}$ shaft modeller.

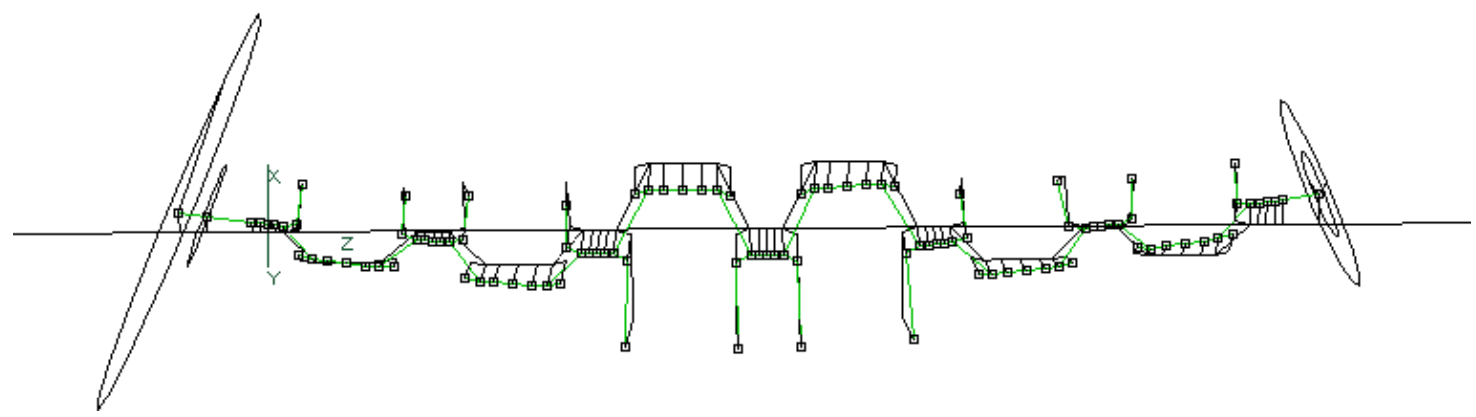

Figure 3. First mode shape (1st bending mode) of a crankshaft.

To decrease the computation time, the connecting rod was modelled with three mass points connected by two elastic bar elements that its property was derived from the real cross-section of connecting rod as input values. About the FE mesh of crankcase, the bearing shell and two rows of element around them were meshed by linear hexahedral elements which have higher flexibility in comparison with tetrahedral elements [7]. Therefore, linear hexagonal elements are used for meshing the journal bearings, and their housings and rest of crankcase are meshed using the linear tetrahedral elements. Cylinder liners, dummy cylinder heads and engine feet are merged into the crankcase FE model and are assumed as an integrated part. The nodes of main bearings thrust and anti-thrust lines of cylinder liners, the flame face of dummy cylinder heads and some nodes in contact with the crankshaft thrust bearings were retained in the condensed model of the crankcase.

Figure 4 shows the 2D schematic of the V12 engine dynamic model in AVL/Excite ${ }^{\circledR}$ software. Figure 5 shows the V12 engine model in AVL/Excite ${ }^{\circledR}$ software. $^{2}$ The global coordinate system is at the centre of the first main bearing (direction of Z-axis points from the flywheel to the damper, Y-axis points to upward, X-axis points to the left looking from flywheel side). Main bearings are numbered from flywheel side to free end. 


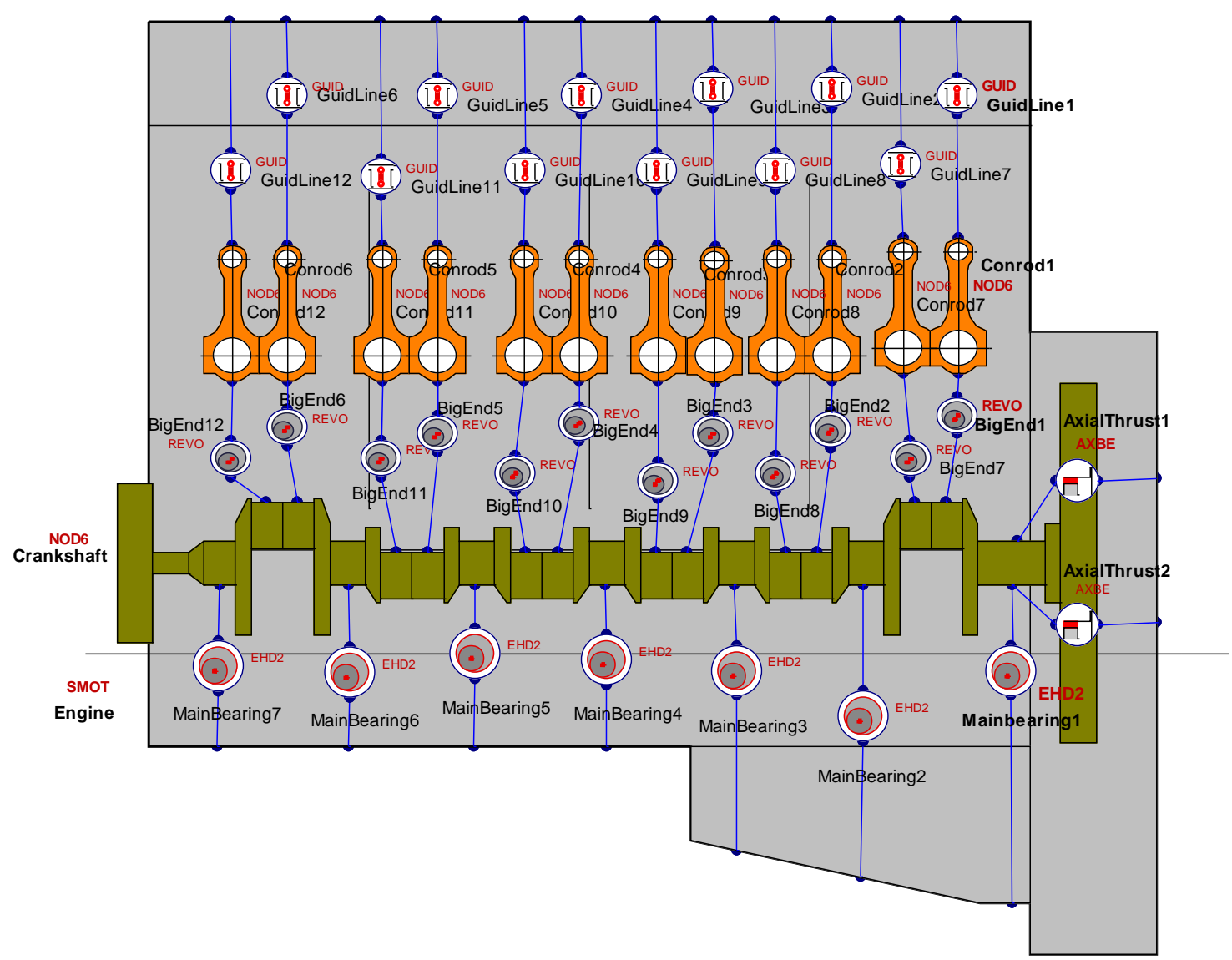

Figure 4. Schematic representation of V12 engine dynamic model.

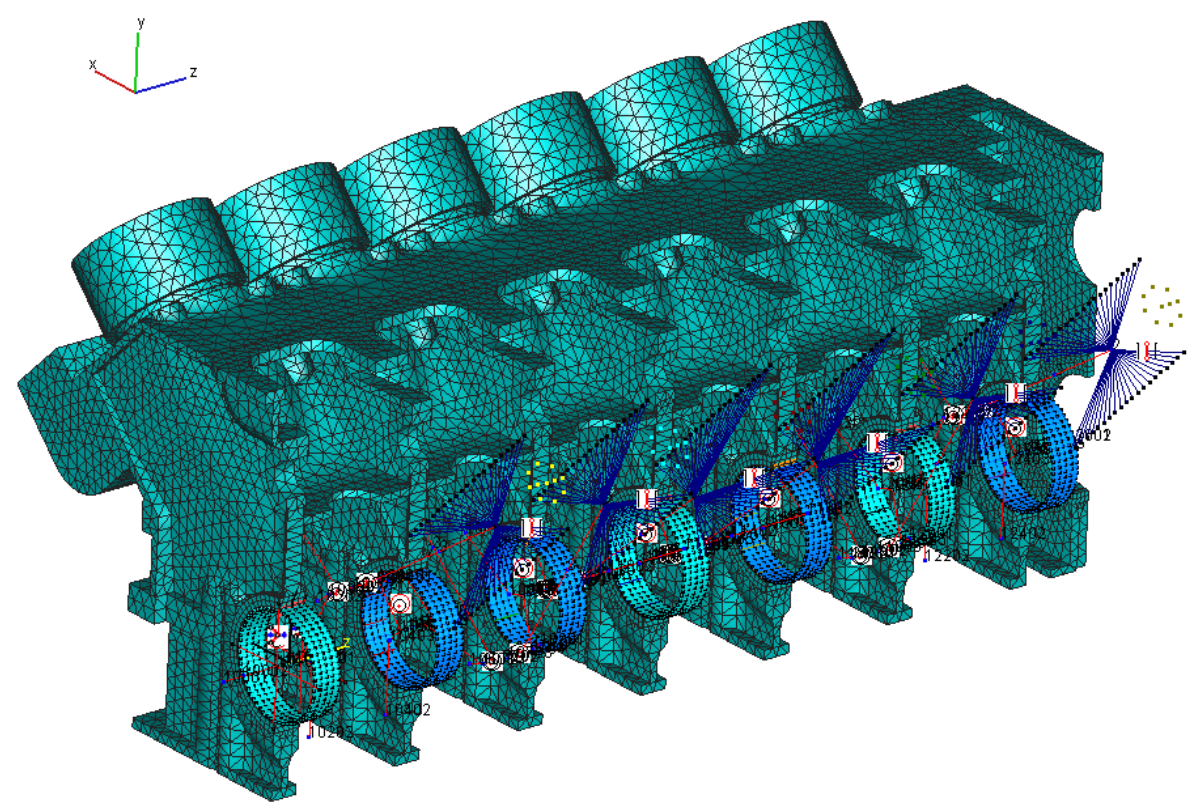

Figure 5. A dynamic model of V12 cylinder engine in AVL/Excite ${ }^{\circledR}$.

REVO joint type is employed in the small end (SE) and big end (BE) of connecting rod. EHD joint type with 21 axial and 181 circumferential finite difference mesh nodes is used for the main bearings. In some cases, main bearings were modelled 
by NONL joints, which are nonlinear spring-damper. Each main bearing has 5 and 60 nonlinear spring elements along the axial and circumferential directions, respectively, where the stiffness distribution over the bearing width is defined by $1: 2: 3: 2: 1$ distribution. The thrust bearing is located adjacent to the main bearing No.1 (near the flywheel).

Peak cylinder gas pressure at $1500 \mathrm{rpm}$ is considered equal to 200 bar. The mean output torque of the engine is internally calculated in AVL/Excite ${ }^{\circledR}$ and automatically applied to the flywheel node. The cylinder gas pressure is applied to the flame face of dummy cylinder heads.

\section{RESULTS AND DISCUSSION}

\section{Simulation Results of the Base Engine}

In this section, the results of the EHD analysis of flexible crankshaft and crankcase are discussed. Figure 6 and Figure 7 show the main bearing forces and moments in lateral (X) and vertical (Y) directions as well as their magnitudes just for main bearings No. 2 and 5. Main bearing forces depend on the engine firing order and crankshaft-crankcase interaction. Due to the elastic deformation of the crankshaft in each firing load case as well as crankshaft tilt, the main bearing moments are generated. Although the main bearing moment, in comparison with the force, has a little impact on the stress distribution of crankshaft and crankcase but can cause the main bearing edge loading, and, consequently affect the oil film pressure distribution. Bearing edge loading can lead to edge wear.

It should be noted that wear is common damage in engine bearing shells, therefore, predicting this damage and providing a solution to prevent this and improve the design are vital in the design process. Therefore, the main bearing moments are important from the aspect of its wear damage. The edge wear usually observed in main bearings is approval of this matter. The location of peak moment of the main bearing can occur either close to peak force of the main bearing, such as main bearings No. 2, 3, 4 and 7, or close to the second extremum of main bearing force such as main bearings No. 1, 5 and 6 .

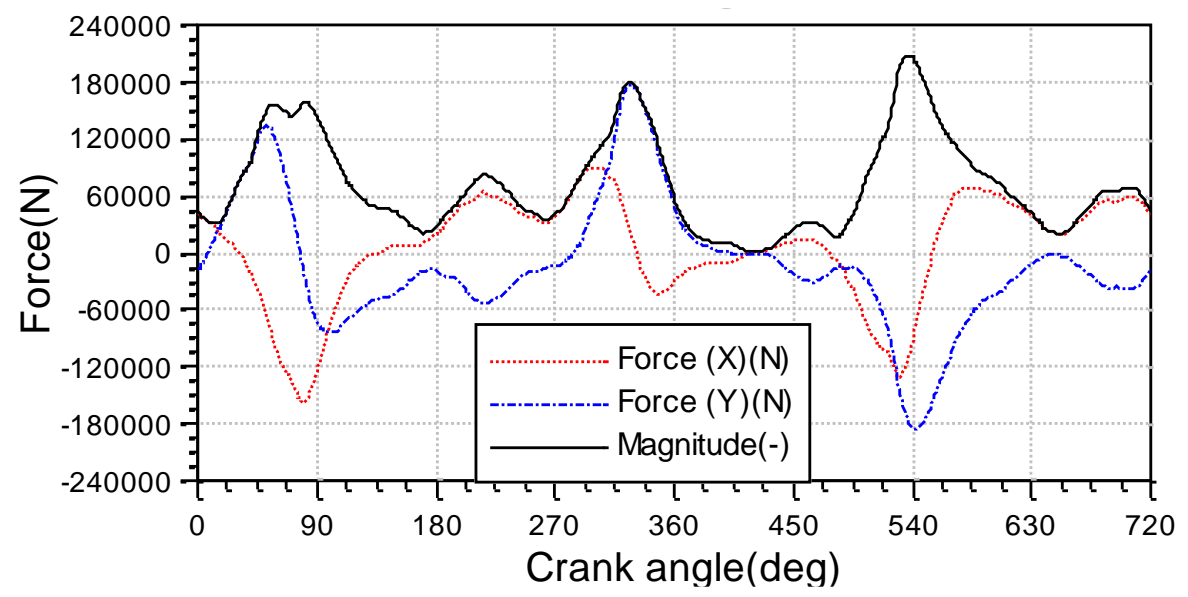

(a) 


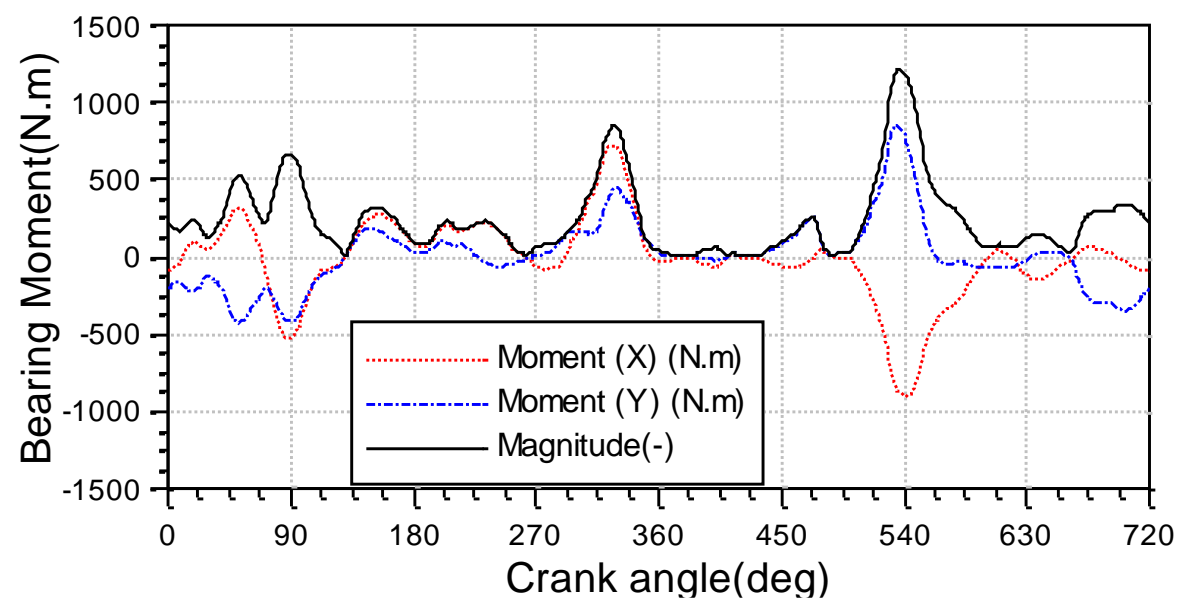

(b)

Figure 6. (a) Force and (b) moment as a function of crank angle in main bearing No. 2.

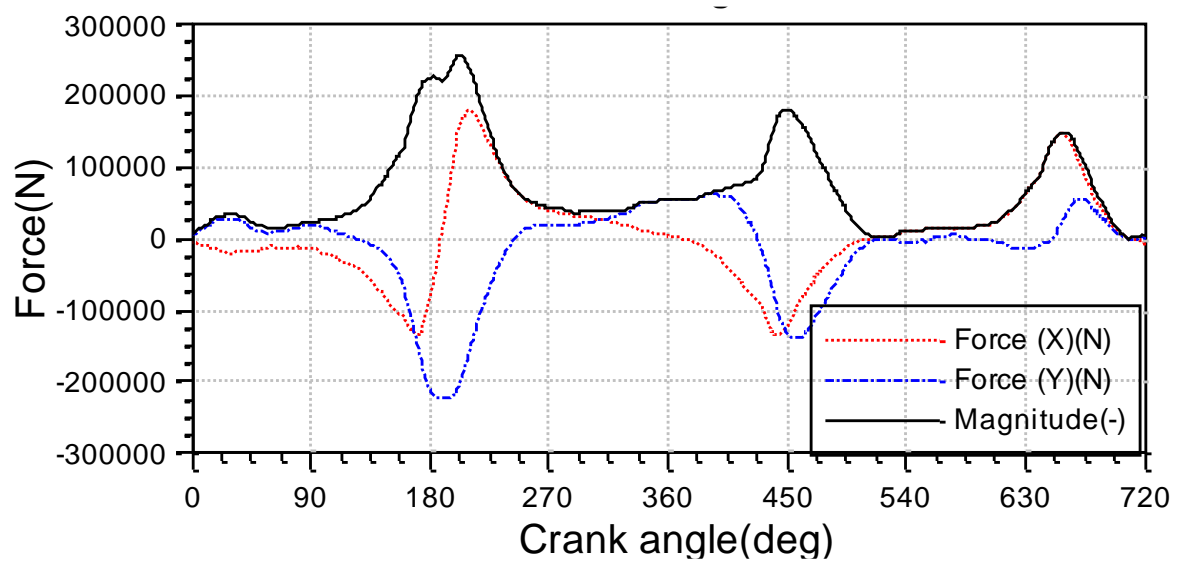

(a)

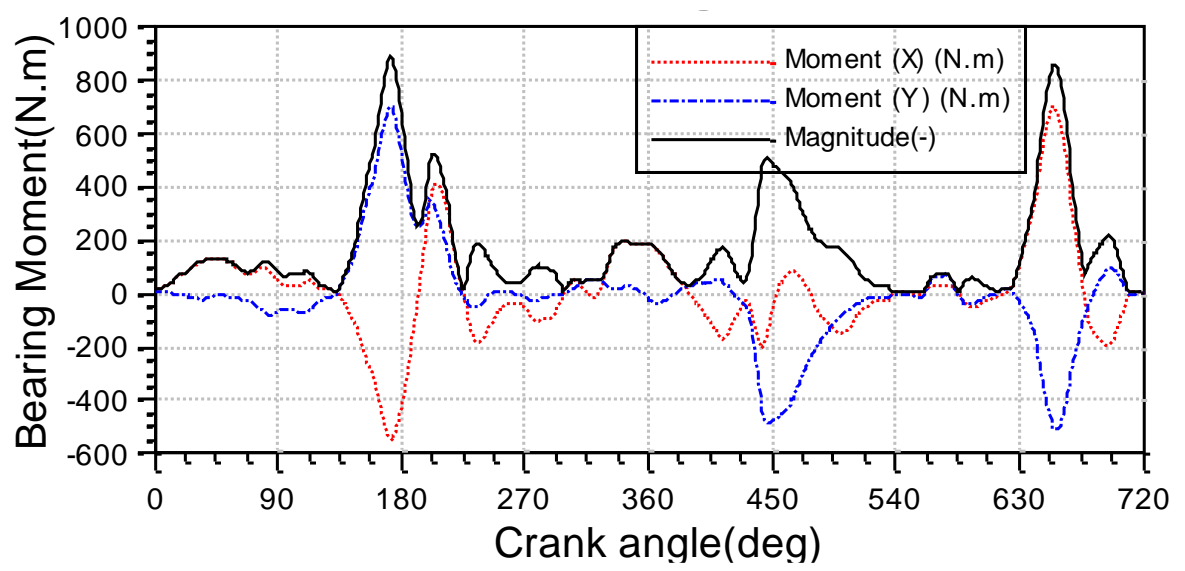

(b)

Figure 7. (a) Force and (b) moment as a function of crank angle in main bearing No. 5.

Figure 8 shows the hydrodynamic pressure distribution of all main bearings, at a selected engine crank angle. Edge loading can be observed for main bearings No. 3, 4 and 5 due to excessive crankshaft tilt and deformation. A split of the hydrodynamic pressure 
profile in the grooved area of the first bearing is also evident. The pressure split usually appears in upper bearing shell, when inertia loading dominates.

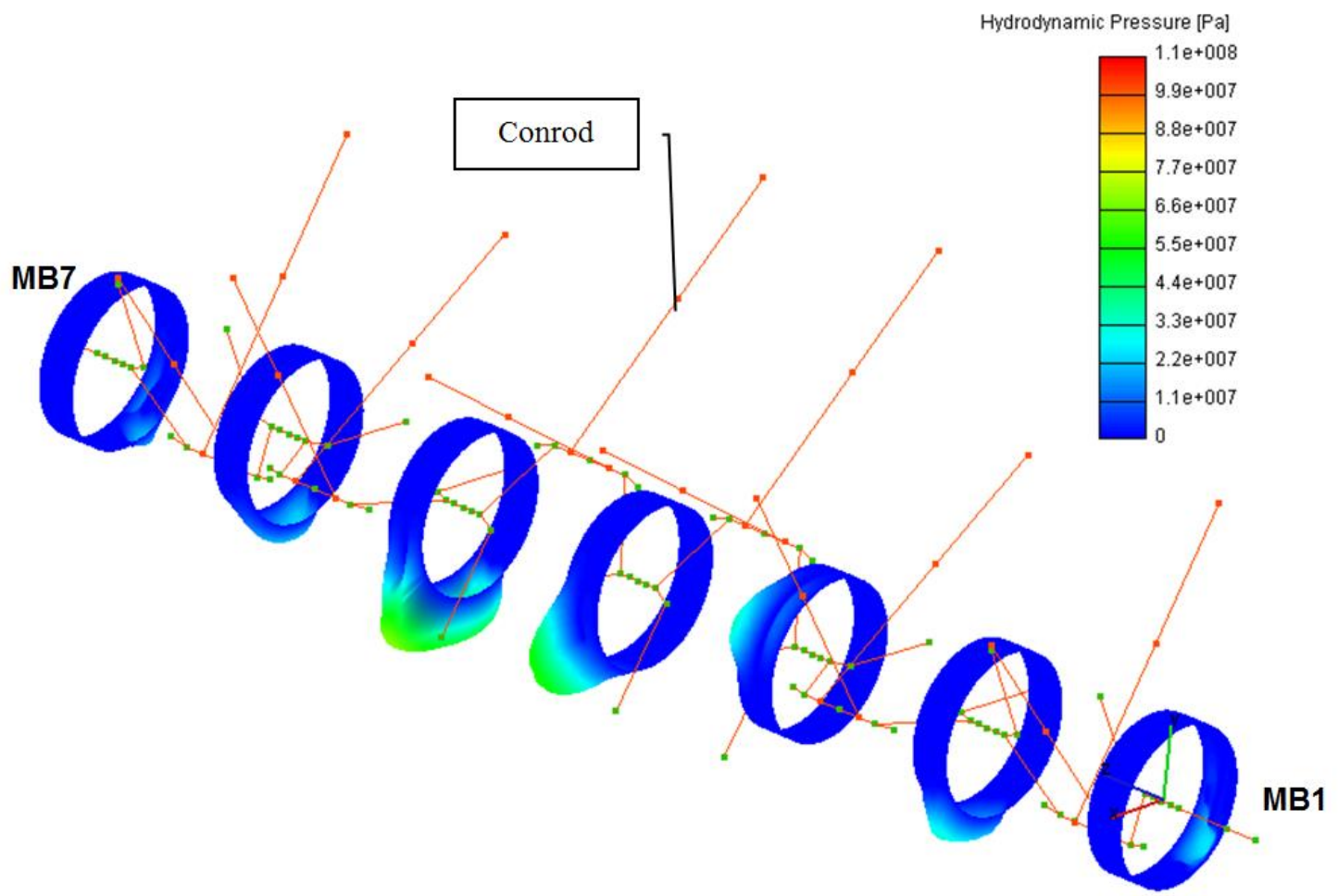

Figure 8. Hydrodynamic oil film pressure distribution on main bearings-EHD analysis.

The rigid body dynamic analysis of crank train was performed using AVL/Designer ${ }^{\circledR}$ and ADAMS/Engine ${ }^{\circledR}$ software. Comparison of maximum main bearing forces calculated by different approaches, i.e. rigid and flexible dynamic analyses, is shown in Figure 9. Considering the under-study engine firing order, the maximum main bearing force happens in main bearing No. 5. Furthermore, the maximum difference between the results of rigid and flexible body dynamic simulations occurs at the same main bearing, lower than $10 \%$. There is main difference between a rigid body and flexible body dynamic analyses in calculating main bearing moment; therefore, just a flexible body dynamic analysis is reliable for that. Figure 10 shows the variation of peak moments on each main bearing. Due to crankshaft tilt, the main bearings at the two ends of crankshaft have the highest bearing moment.

\section{Effect of Crankshaft Flexibility}

The crankcase is assumed to be rigid, and just the crankshaft flexibility is taken into account. The crankshaft stiffness is altered by a change in Young modulus of its material. Very flexible crankshaft, denoted as the soft crankshaft, and very stiff crankshaft, denoted as the stiff crankshaft, are considered to study, and the results of them are compared with the base crankshaft results. Table 1 presents the different Young modulus of the material to consider soft, base and stiff crankshaft. Figure 11 compares the maximum main bearing force considering different crankshaft flexibilities. Soft crankshaft causes the higher crank throw deformation, therefore, leads to force on crank pin and, subsequently, on the 
connecting rod. The force is distributed on adjacent main bearings, and thus the maximum main bearing forces increase. But, the stiff crankshaft leads to lower deformation of the crank throw. In this case, the applied force on crank throw distributes over the all main bearings, and thus the maximum main bearing forces decrease. Crankshaft flexibility has a major effect on main bearing force and moment and, therefore, it influences the lubrication performance of main engine bearings. For this reason, the crankshaft flexibility must be considered in the dynamic analysis of engine crank train.

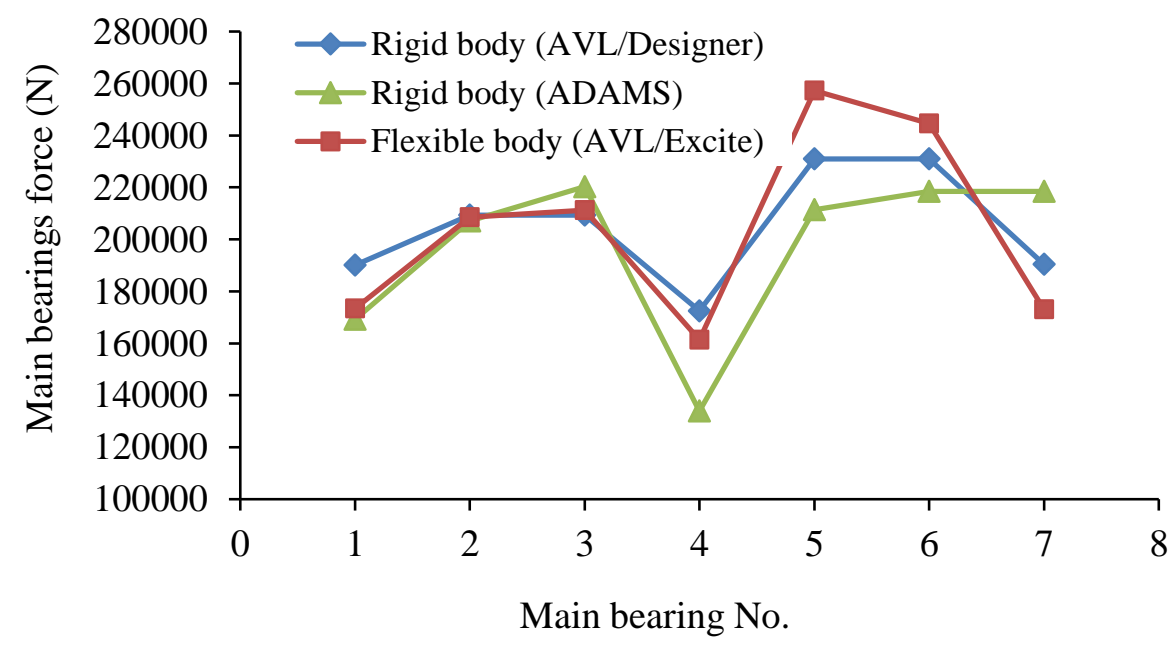

Figure 9. Comparison of maximum main bearing force calculated with a different approach.

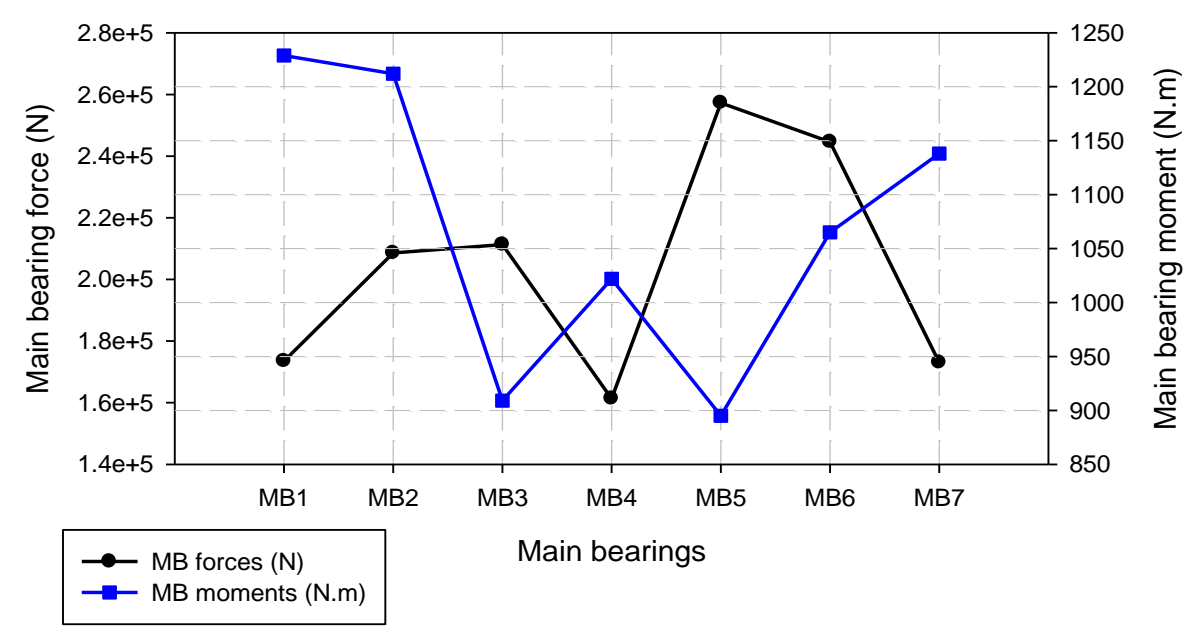

Figure 10. Graph of peak force of main bearing and moment in case of flexible crankshaft and crankcase.

Table 1. Different Young modulus of the material to consider soft and stiff crankshaft.

\begin{tabular}{cc}
\hline Case & Young modulus $(\mathrm{GPa})$ \\
\hline Soft & 102.5 \\
Base & 205 \\
Stiff & 410 \\
\hline
\end{tabular}




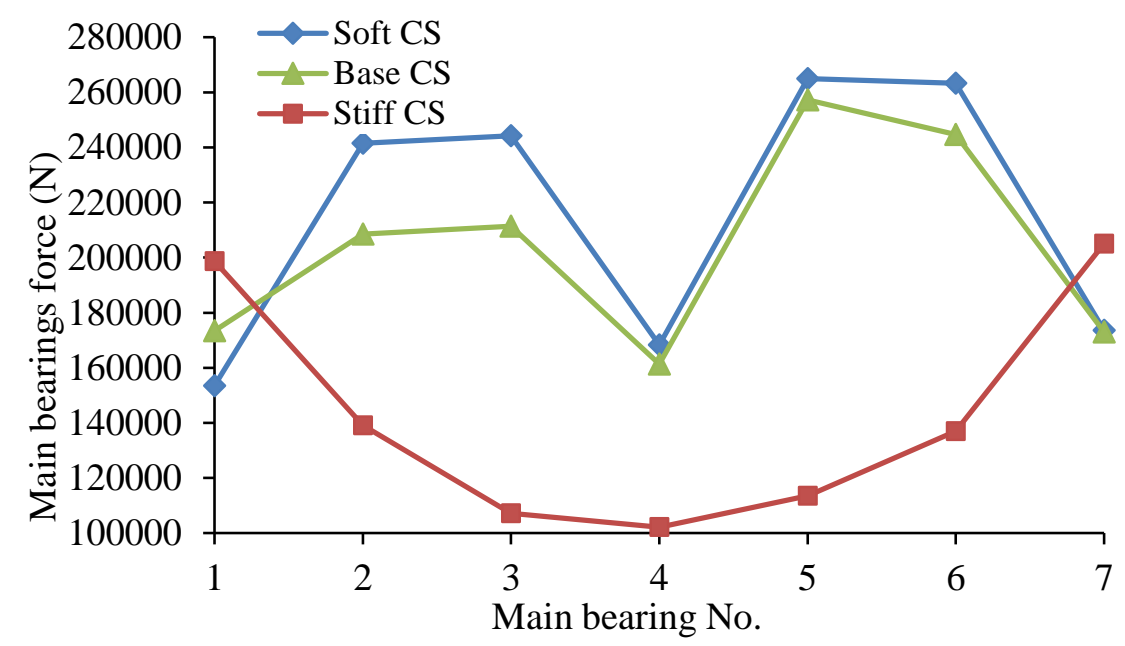

Figure 11. Comparison of maximum main bearing force considering different crankshaft flexibilities.

The amount of force applied to the crankshaft main bearings is affected by the firing order, and distribution of force applied to the crankshafts throws in the main bearings of the engine. The firing order of the engine being studied is A1-B2-A5-B4-A3B1-A6-B5-A2-B3-A4-B6, where A-bank in on the left side of the engine and B-bank is located on the right side of the engine if viewed at the engine from the flywheel side.

The main bearings no. 1 and 7, which are at the two ends of the crankshaft, experience less force than the other bearings, because the force exposed to the crank through the adjacent cylinder is applied on the two bearings. For the other engine main bearings, the force applied on the adjacent cranks of the bearing, caused by combustion in adjacent cylinders, increased the force. Therefore, when the compressive force applied to the adjacent cranks of the main bearing through the adjacent cylinders is greater, that bearing experienced a more compressive force. For the under-study engine, the firing order is in such a way that the maximum force is applied on the main bearings no. 3 and 5 , and the minimum one is applied on the main bearing no. 4 .

\section{Effect of Crankcase Flexibility}

To investigate the effect of crankcase stiffness on main bearing force and moment, some different geometry models of crankcase are considered. The following cases are studied from simple to a full, complicated geometrical model of crankcase assembly:

- Case 1: Rigid crankcase

- Case 2: Spring element

- Case 3: Single main bearing wall

- Case 4: Bottom section of crankcase assembly

- Case 5: Full assembly of crankcase

\section{Case 1: rigid crankcase}

The crankcase was considered as a rigid body, i.e. ANCH type body. Therefore, the crankcase stiffness is infinite. Just the nodal positions of main bearings and cylinder axis, i.e. cylinder liners should be defined. Figure 12 shows the Global engine model with the rigid crankcase. Using rigid crankcase has some benefits. First is the decrease in 
computation time due to the elimination of mass and stiffness matrix of the crankcase. Secondly, the crankcase is defined just by the location of the main bearing centre and cylinder axis as an ANCH body type. Thirdly, the results obtained from this analysis, including hydrodynamic oil film pressure and oil film thickness, can be used for the concept design stage.

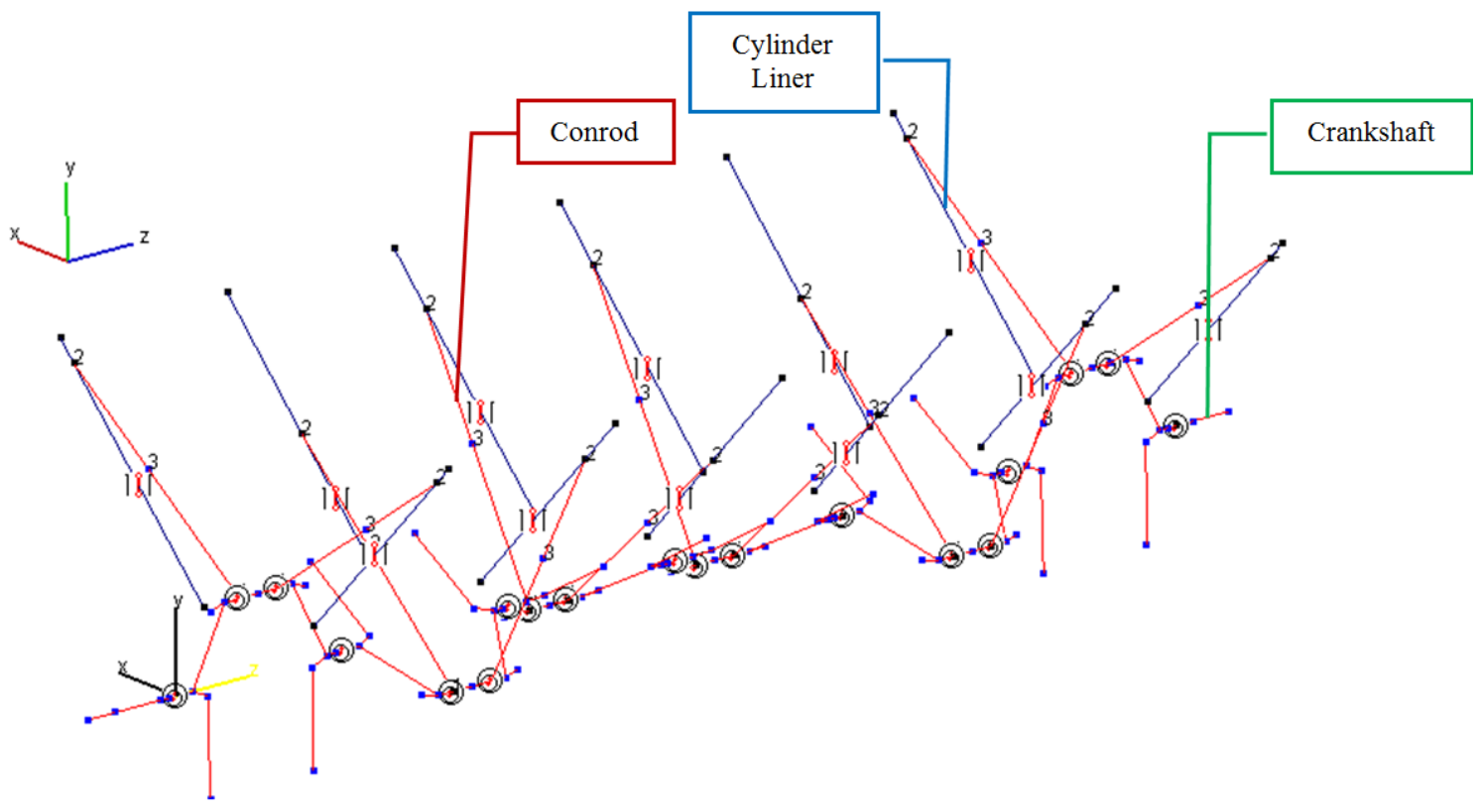

Figure 12. Global engine model with rigid crankcase-V12.

\section{Case 2: spring element}

In this case, the equivalent stiffness of the main bearing wall in different directions was calculated using FE analysis. A section of crankcase assembly, i.e. main bearing wall, was separated from the crankcase assembly. The model was constrained at the normal direction of cutting faces. The bearing load was applied on the main bearing bore, and its deformation was calculated. Figure 13 indicates the variation of radial stiffness of the main bearing wall in different directions. The zero angle of bearing shell is assumed to be at the top. The stiffness of the main bearing in the vertical direction is higher than lateral direction. Also, the stiffness of the main bearing wall under the applied moments $M_{x}, M_{y}$ and $M_{z}$ was calculated. The schematic representation of the V12 engine dynamic model using spring elements as main bearing walls is shown in Figure 14.

\section{Case 3: single main bearing wall}

In this case, the main bearing wall is directly accounted into simulation, and itself is meshed using FE. One main bearing wall is meshed and constrained at the top and side of cutting faces; then, its condensed model is generated using sub-structure analysis. The condensed mass and stiffness matrix of one main bearing wall is used for all main bearing walls, as shown in Figure 15. In the dynamic engine model, the liner guidelines, i.e. cylinder axis, are defined using an ANCH body. 


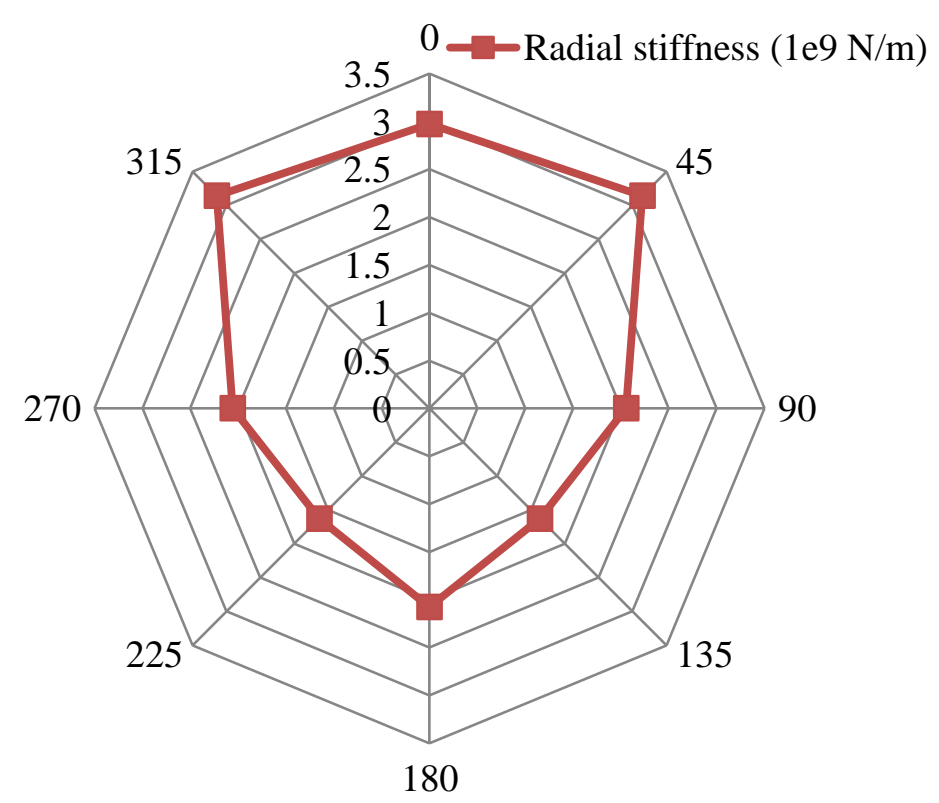

Figure 13. Polar diagram of a variation of radial stiffness $(1 \mathrm{e} 9 \mathrm{~N} / \mathrm{m})$ of the main bearing wall in different directions (zero angle is related to the vertical axis).

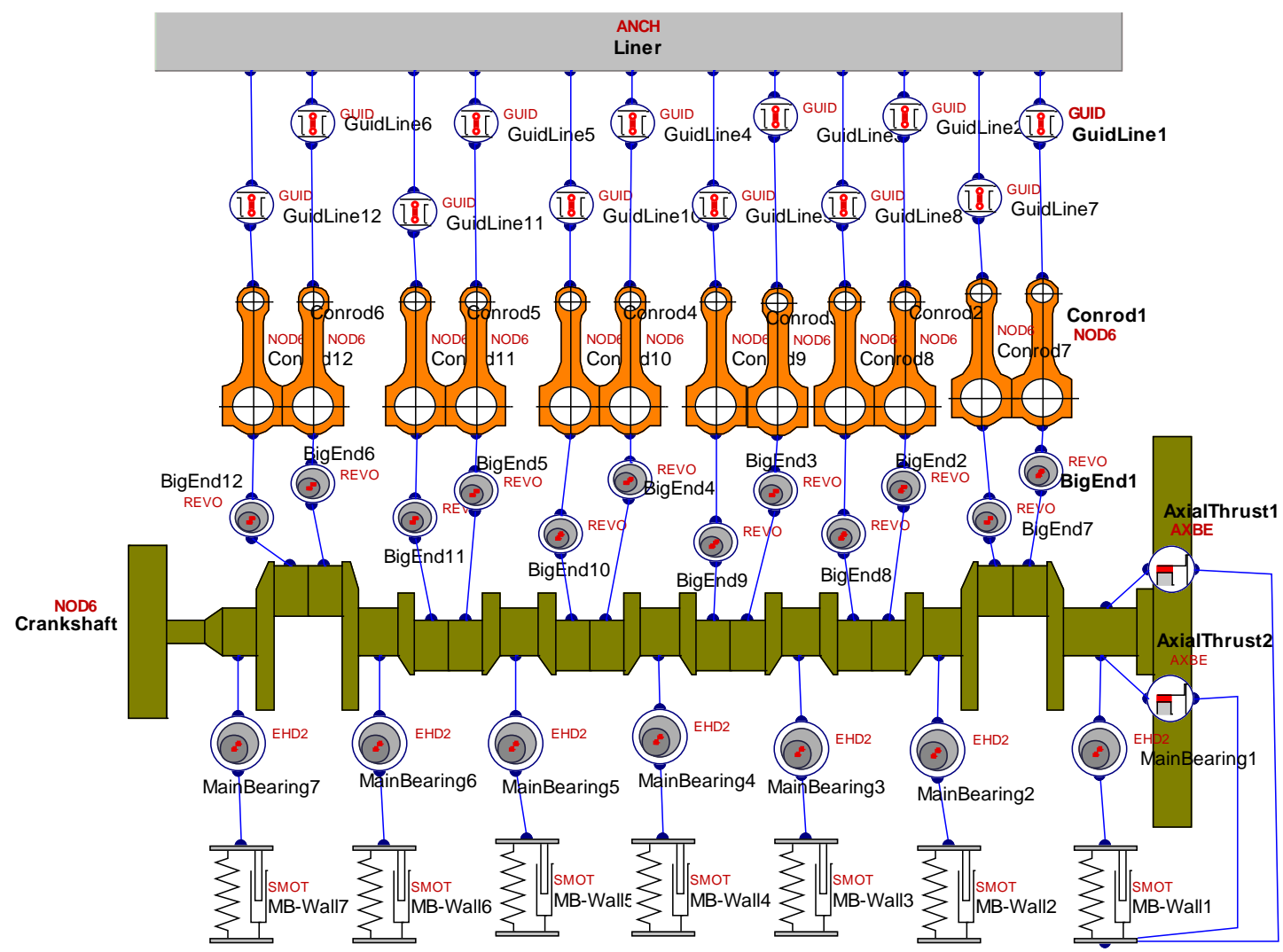

Figure 14. Schematic representation of V12 engine dynamic model using spring elements as main bearing walls. 


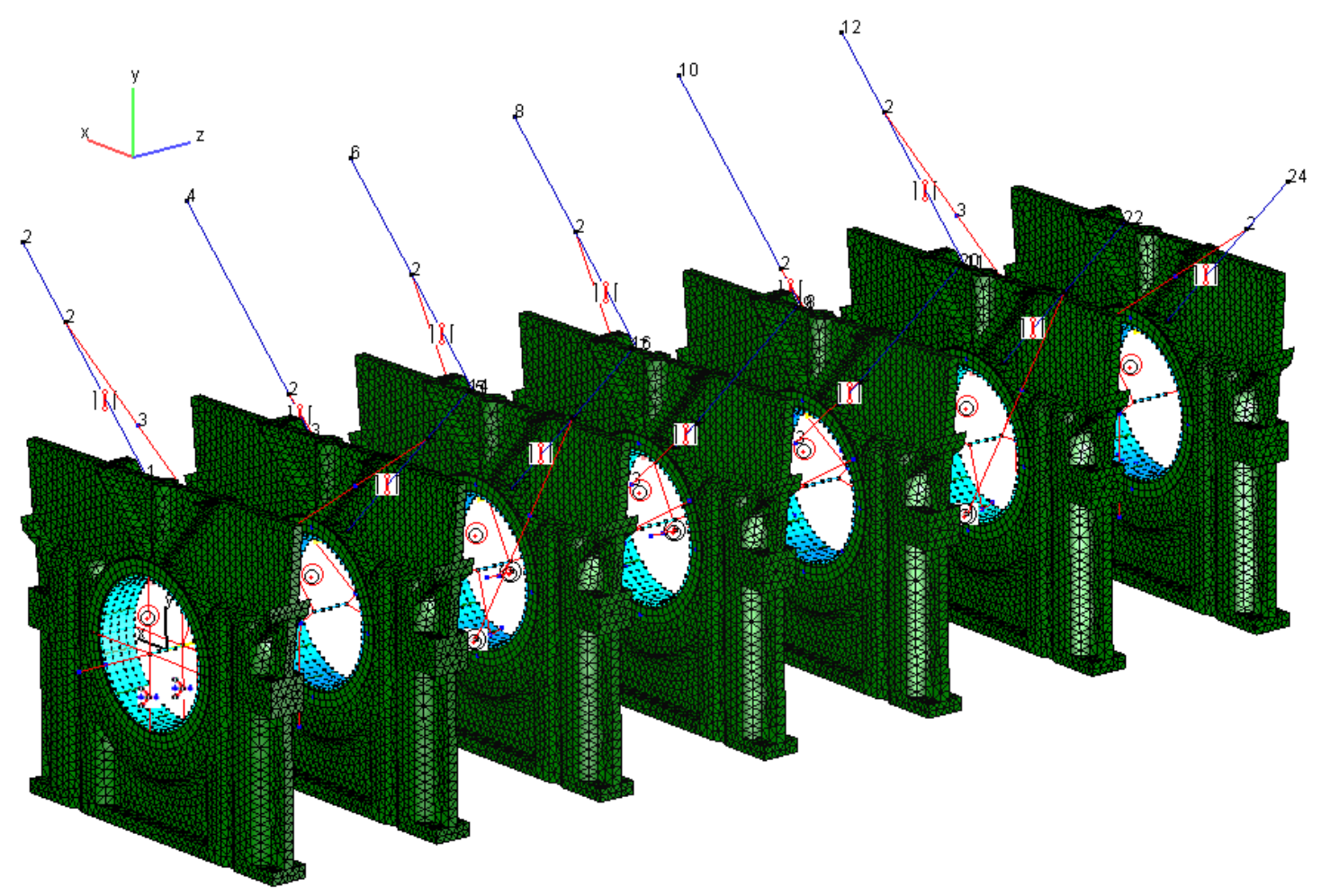

Figure 15. FE mesh and 3D representation of V12 engine dynamic model using single main bearing walls.

Case 4: bottom section of crankcase assembly

In this case, the bottom section of crankcase assembly was considered as the engine crankcase. In the under-study engine, the bearing caps have been installed on a ladder frame, and it is bolted to the crankcase.

\section{Case 5: full assembly of the crankcase}

In this case, the full assembly of engine crankcase, cylinder liners and dummy cylinder heads are considered as the engine crankcase. Figure 16 illustrates the graph of force versus crank angle for main bearing No.5 considering different crankcase flexibility models. The main bearing forces of case 1 and case 2 are approximately the same but are different from case 3,4 and 5. Results reveal that, regarding main bearing forces, case 3 has enough accuracy and is almost similar to the results obtained from the full assembly of the crankcase. Therefore, regarding main bearing force, just main bearing walls are needed to consider as the flexible crankcase. The main bearing wall is designed at the first stage of engine design. Therefore, accurate main bearing forces can be obtained if the main bearing wall is included in the crank train dynamic analysis. 


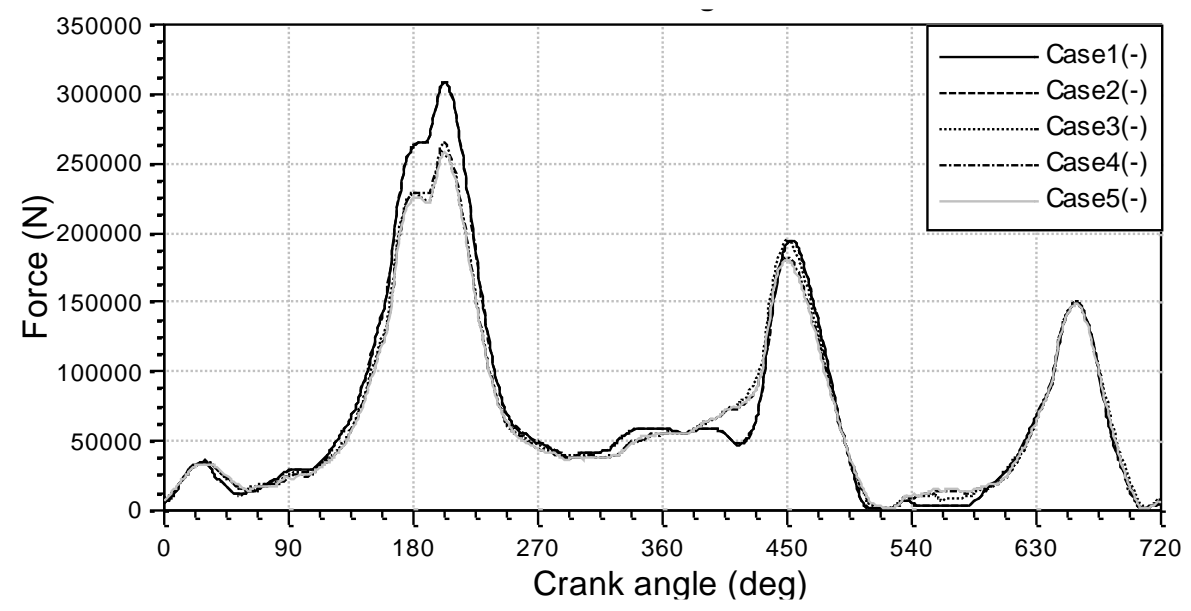

Figure 16. Graph of force versus crank angle for main bearing No. 5 in different cases.

Figure 17 shows the graph of moment versus crank angle for main bearing No. 2 in different cases. Case 1 and 2 have a major difference with other cases and estimate higher main bearing moment. Similar to the main bearing force, the results of case 3 is acceptable regarding the main bearing moment. It is proposed that to obtain relatively accurate main bearing force and moment, at least the main bearing wall should be included in the dynamic crank train analysis.

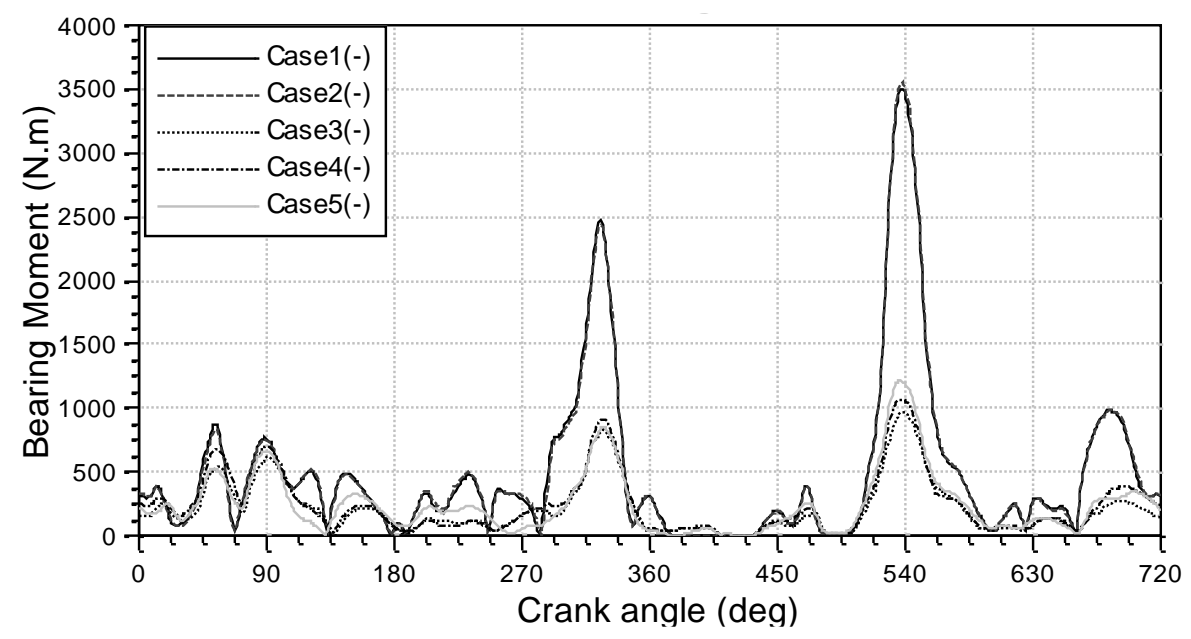

Figure 17. Graph of moment versus crank angle for main bearing No. 2 in different cases.

\section{CONCLUSION}

In this paper, the flexible, dynamic analysis of V12 heavy-duty diesel engine was performed using AVL/Excite ${ }^{\circledR}$ software. The effects of crankshaft and crankcase stiffness on main bearing forces and moments were investigated. Results reveal that the crankshaft flexibility has a major effect on main bearing force and moment. Therefore, the crankshaft flexibility must be considered in the dynamic analysis of engine crank train. It is proposed that, to obtain relatively accurate main bearing forces and moments, at least the main bearing wall should be included in the dynamic crank train analysis as the flexible crankcase body. 


\section{REFERENCES}

[1] Jakobsson B, Floberg L. The finite journal bearing, considering vaporization. Sweden: Transactions of Chalmers University of Technology; 1957.

[2] Maas H. Calculations of crankshaft plain bearings. In ClMAC-Congress, Stockholm, Sweden, pp. 214-222; 1971.

[3] Piraner I, Pflueger C, Bouthier O. Cummins crankshaft and bearing analysis process. In North American MDI user conference, US, pp. 98-110; 2002.

[4] Myung-Rae C, Dae-Yoon O, Seung-Hyuk R, Dong-Chul H. Load characteristics of engine main bearing: Comparison between theory and experiment. KSME international journal. 2002;16(8):1095-101.

[5] Knoll G, Schönen R, Wilhelm K. Full dynamic analysis of crankshaft and engine block with special respect to elasto-hydrodynamic bearing coupling. ASME ICE. 1997;28(3):1-8.

[6] Mourelatos ZP. An efficient crankshaft dynamic analysis using substructuring with Ritz vectors. Journal of Sound and vibration. 2000;238(3):495-527.

[7] Maass H, Wieler R. The effect of crankcase elasticity on main bearing behaviour and crankshaft stress. In Proceedings of the 20th International Congress on Combustion Engines, London, England, pp. 3-13; 1993.

[8] Cicek K, Celik M. Application of failure modes and effects analysis to main engine crankcase explosion failure on-board ship. Safety Science. 2013;51(1):610.

[9] Pratik K, Pasarkar MD, Thakur AG. Static Analysis of Crankcase and Crankshaft of Single Cylinder Four Stroke Diesel Engine. International Journal on Recent Technologies in Mechanical and Electrical Engineering 2015; 1(5):1-5.

[10] Rozhdestvensky Y, Khozeniuk N, Surovtsev S. Dynamics and Lubrication Problem Analysis of Main Bearings for IC Engines Based on Coupling between a Crankshaft and a Flexible Whole Engine Block. Tribology in Industry 2018;40(1):139-148.

[11] AVL-Excite ${ }^{\circledR}$, Reference Manual, Version 6.1; accessed June 2004.

[12] Bonneau D, Guines D, Frene J, Toplosky J. EHD analysis, including structural inertia effects and a mass-conserving cavitation model. Journal of Tribology. 1995;117(3):540-547.

[13] Garnier T, Bonneau D, Grente C. Three-dimensional ehd behavior of the engine block/crankshaft assembly for a four-cylinder inline automotive engine. Journal of tribology 1999;121(4):721-30.

[14] Zhang J, Dong Q. Lubrication performance analysis of crankshaft bush in compressor. Engineering Failure Analysis. 2018;90(1):277-89.

[15] Yilmaz Y, Anlas G. An investigation of the effect of counterweight configuration on main bearing load and crankshaft bending stress. Advances in engineering software 2009;40(2):95-104.

[16] Karimaei H, Chamani H. Study of cavitation and wear damages in conrod big end bearing of a heavy-duty diesel engine by using elasto-hydrodynamic method. In ASME 2009 Internal Combustion Engine Division Fall Technical Conference, Lucerne, Switzerland, pp. 553-565; 2009. 